\title{
OCCURRENCE OF LISTERIA MONOCYTOGENES IN FOOD IN SRI LANKA
}

\author{
DEEPTHI K. GUNASENA, CHANDRA P. KODIKARA, KUMUDU GANEPOLA \\ and S. WIDANAPATHIRANA \\ Department of Microbiology, University of Kelaniya, Kelaniya.
}

(Received: 18 January 1995; accepted: 07 July 1995)

\begin{abstract}
A study on the occurrence of Listeria monocytogenes in market samples of different food items indicated that $38 \%$ of the samples contained $L$. monocytogenes. The percentage of positive samples was highest among vegetables $(49 \%)$, second in chicken $(34 \%)$ and lowest in dairy products $(26 \%)$ Inactivation of $L$. monocytogenes during cooking of green leaves indicated that $L$. monocytogenes was recovered from samples upto $8 \mathrm{~min}$ of cooking by which time the temperature was $72^{\circ}$ C. L. monocytogenes strains isolated had haemolytic activity of 16 to 64 minimal haemolysis units by the microhaemolysis test.
\end{abstract}

Key words: Listeria monocytogenes, food, heat inactivation.

\section{INTRODUCTION}

Listeria monocytogenes is a gram positive, motile, non-sporeforming rod which is ubiquitous in nature. It causes severe infections in man, with case fatality rates of $11 \%$ under forty years of age and $63 \%$ over 60 years of age. ${ }^{1}$ This organism is capable of slow multiplication at refrigeration temperatures ${ }^{2}$ and it is tolerant to preserving agents such as $16-20 \%$ sodium chloride ${ }^{3,4}$ and $120 \mathrm{ppm}$ sodium nitrite. ${ }^{5}$ On the basis of microbiological and epidemiological evidence, a wide range of foods have been associated with human listeriosis; e.g. raw or undercooked chicken, ${ }^{6}$ pasteurized milk, ${ }^{7}$ raw vegetables ${ }^{8}$ and soft cheese. ${ }^{9}$ This has led to a growing interest in surveying food for the presence of $L$. monocytogenes. Its presence in food or food-borne outbreaks of listeriosis have not been reported in Sri Lanka.

The objective of the present study was to determine the presence of L. monocytogenes in certain food items which have been implicated as sources of food-borne listeriosis in other countries. A preliminary study carried out to determine the efficiency of the isolation technique indicated that some green leaves, gotukola (Centella asiatica) and mukunuwanna (Alternanthera sessilis) which are used as vegetables, are highly contaminated with $L$. monocytogenes. Therefore the present study also determined its survival during partial cooking of green leaves in the preparation of mallun (a local preparation made by briefly heating vegetables and grated coconut).

Since haemolysis of $L$. monocytogenes has been identified as a virulence factor, ${ }^{10}$ the study aimed also to determine the haemolytic activity of local strains isolated. 


\section{METHODS AND MATERIALS}

Sampling: A total of 139 samples of food which included fresh and frozen chicken, vegetables and dairy products were obtained from retail shops in Colombo, Dalugama, Gampaha and Kiribathgoda. The retail outlets from which the samples were obtained included supermarkets, farm shops, groceries, milk booths and public markets.

Isolation of L. monocytogenes: A $25 \mathrm{~g}$ sample of food was homogenized and incubated in Listeria enrichment broth. ${ }^{11}$ After $24 \mathrm{~h}$ of incubation, broth was plated on to Listeria selective agar. ${ }^{12}$ Typical colonies were subcultured on nutrient agar and identified using the criteria of McLauchlin (1987). ${ }^{13}$ The morphological characters used in identification were gram positive, non-sporing, non-capsulated, non-pigmented and non-acidfast features of the isolates. The biochemical tests used in identification were catalase, oxidase, methyl red and Voges-Proskauer tests, haemolysis on sheep blood agar, CAMP test with Staphylococcus aureus and Rhodococcus equi, fermentation of carbohydrates (adonitol, arabinose, glycogen, mannitol, xylose, L-rhamnose, D-glucose, trehalose and salicin), indole production, nitrate reduction and gelatin, aesculin and casein hydrolysis. L. monocytogenes ATCC 19111 obtained from the Czechoslovakian Culture Collection (National Institute of Public Health, Czechoslovakia) served as a reference strain.

Quantitation of haemolytic activity (Microhaemolysis test): The microplate technique ${ }^{14}$ was performed on all isolates to quantitate the haemolytic activity due to listeriolysin. Minimal Haemolysis units/MHU (the reciprocal of the highest dilution at which haemolysis was obtained) of each isolate was determined.

Study on inactivation of L. monocytogenes during cooking of green leaves: With the object of reproducing conditions of mallun preparation the time and temperature required for preparation of mallun was noted by heating fresh green leaves with coconut until they were partially cooked. Two samples of $250 \mathrm{~g}$ chopped mukunuwanna (Alternanthera sessilis) which had been autoclaved were inoculated with a culture of $L$. monocytogenes $\left(10^{6} \mathrm{organisms} / \mathrm{g}\right)$ and heated for $10 \mathrm{~min}$ to $82^{\circ} \mathrm{C}$. Duplicate samples were removed for analysis of $L$. monocytogenes and temperature was recorded at 2 min intervals during the heating period of $10 \mathrm{~min}$. The temperatures at 2 min intervals were $40,53,60,72$ and $82^{\circ} \mathrm{C}$.

\section{RESULTS}

\section{Isolation and characterization of L. monocytogenes}

The initial identification of $L$. monocytogenes from food was based on the characteristic appearance of colonies on Listeria selective agar. The results of inorphological and biochemical tests on food isolates were comparable with the reference strain L. monocytogenes (ATCC 19111). 


\section{The occurrence of $L$. monocytogenes in food samples}

L. monocytogenes was recovered from 52 samples out of 139 samples (38\%) of food items tested (Table 1). The highest percentage of positives were observed in vegetables $(49 \%)$, second in chicken $(34 \%)$ and lowest in dairy products $(26 \%)$.

Table 1: Occurrence of L. monocytogenes in food.

\begin{tabular}{|c|c|c|}
\hline Type of Food & $\begin{array}{l}\text { Number of } \\
\text { samples } \\
\text { examined }\end{array}$ & $\begin{array}{c}\text { Number \& Percentage } \\
\text { of samples positive } \\
\text { for } L \text {. monocytogenes }\end{array}$ \\
\hline
\end{tabular}

Raw chicken

38

$13(34 \%)$

(Fresh \& Frozen)

Vegetables

Green leaves $\quad 17$

$6(33 \%)$

Cabbage $\quad 18$

Lettuce

20

$10(50 \%)$

Milk products

Processed cheese

$\begin{array}{lll}\text { (local) } & 2 & 0 \\ \text { (imported) } & 2 & 0\end{array}$

Cottage cheese

(local) 110

Pasteurized milk $\quad 16$

Raw milk 12

Ice cream (local) 12

Fresh cream (local)

$6 \quad 5(31 \%)$

$23(25 \%)$

$12 \quad 4(33 \%)$

$1 \quad 0$

Total

139

$52(38 \%)$

\section{Quantitation of haemolytic activity (Microhaemolysis test)}

The minimal haemolysis units of isolates ranged from 16 to 64 with a mean of 38.85. The L. monocytogenes control strain (ATCC 19111) gave a MHU of 16.

\section{Inactivation of $L$. monocytogenes during cooking of green leaves}

The actual temperature reached during cooking of green leaves into a mallun was about $69^{\circ} \mathrm{C}$ and the time of heating was $6 \mathrm{~min}$. When the conditions of mallun preparation was reproduced with test samples of green leaves, $L$. monocytogenes was recovered from samples upto $8 \mathrm{~min}$ of cooking by which time the temperature was $72^{\circ} \mathrm{C}$. 


\section{DISCUSSION}

This study is the first report of the isolation of $L$. monocytogenes from food in Sri Lanka. The haemolytic activity of $L$. monocytogenes is used in routine typing of $L$. monocytogenes. The haemolytic activity of $L$. monocytogenes local isolates (16$64 \mathrm{MHU}$ ) were within the range of reported minimum haemolytic activity (12$192 \mathrm{MHU}$ ) of L. monocytogenes. ${ }^{14}$ The other species of Listeria which showed haemolytic activity were $L$. seeligeri and $L$. ivanovii with MHU of 3-6 and 384 respectively. ${ }^{14}$

The occurrence of $L$. monocytogenes in raw chicken has been widely studied. The reported contamination levels of raw chicken by L. monocytogenes in U.K. ${ }^{39}$ U.S.A., ${ }^{15}$ Denmark $^{16}$ and Switzerland ${ }^{17}$ are $60 \%, 23.3 \%, 47.1 \%$ and $12 \%$ respectively. The contamination of poultry products, is due to listeriosis in poultry, asymptomatic healthy carriers ${ }^{16}$ and contamination of carcasses via work surface and equipment. ${ }^{18,19}$ A survey in U.K. showed that $12 \%$ of cooked readyto-eat chicken too contained $L$. monocytogenes. ${ }^{20}$ L. monocytogenes is not especially heat resistant and is killed at normal pasteurization temperature. ${ }^{21-23}$ Therefore listeriosis due to cooked poultry ${ }^{24}$ is linked either to inadequate cooking or recontamination after cooking. The results of the present study too indicates that $34.2 \%$ of raw chicken samples contained L. monocytogenes. However the Sri Lankan practice of thoroughly cooking chicken in the form of chicken curry probably reduces the risk of listeriosis through poultry meat. Nevertheless fast food outlets serving various other preparations of poultry meat may pose a threat as poultry meat may be inadequately cooked.

Raw vegetables are considered as an important vehicle of listeriosis. A large outbreak of listeriosis in 1981 was due to the use of contaminated cabbage in the preparation of coleslaw in Halifax, Canada. ${ }^{25}$ Raw vegetables have caused outbreaks in Boston, U.S.A. ${ }^{8}$ and in Australia. ${ }^{26}$ A study on the occurrence of $L$. monocytogenes in raw retail vegetables in U.K. in 1987/1988 indicated that cabbage, cucumber, potatoes and raddish were contaminated. The percentage of positive samples varied from 1.1 to $21.2{ }^{27}$ In the present study of vegetables the isolation was highest from green leaves (gotukola-Centella asiatica, mukunuwannaAlternanthera sessilis, kankun-Ipomoea aquatica, sarana-Trianthemadecandra). $L$. monocytogenes can easily propagate in nature and can maintain a nonzoonotic life cycle in soil, water and vegetation. ${ }^{16,28}$ It has also been shown that this organism does not lose virulence during long storage periods in soil. ${ }^{29}$ Since green leaves are grown in low lying areas with plenty of water it is possible that these conditions facilitate contamination with $L$. monocytogenes. ${ }^{28}$

The practice of eating green leaves either raw or partially cooked as mallun is common in Sri Lanka. The present study indicated that $L$. monocytogenes was probably not inactivated during the preparation of a mallun. Cooking time and temperature should exceed $8 \mathrm{~min}$ and $72^{\circ} \mathrm{C}$ respectively in order to inactivate a heavy inoculum of $L$. monocytogenes. Lettuce and cabbage too were found to be contaminated and adequate precautions should be taken when preparing salads. It has been shown that when vegetables are held at $4^{\circ} \mathrm{C}$ for $4 \mathrm{~d}$ the 
population of $L$. monocytogenes can increase twofold. ${ }^{30}$ None of the vegetables used in the present study were refrigerated, but use of refrigeration as in supermarkets and homes increases the risk due to multiplication during refrigerated storage.

Presence of $L$. monocytogenes in raw milk has been reported in Netherlands (4.4\%), ${ }^{31}$ U.S.A. $(4.5 \%),{ }^{11}$ Canada(1.3\%), ${ }^{23}$ Scotland $(2.6 \%)^{32}$ and Spain $(45.3 \%) .{ }^{33}$ It is eliminated by normal high temperature short time pasteurization ${ }^{34-36}$ and its presence in pasteurized milk is either due to inadequate heating or post pasteurization contamination. Contamination of pasteurized milk in U.K. $(1.1 \%)^{37}$ and Northern Ireland $(1.05 \%)^{38}$ by L. monocytogenes has been reported. Presence of this organism in local pasteurized milk is highly significant. A study of soft cheese in U.K. showed the occurrences of L. monocytogenes in soft cheese manufactured in different countries were $14 \%$ in France, $4 \%$ in U.K., $16 \%$ in Italy and $10 \%$ in Cyprus. ${ }^{39}$ The only local soft cheese available was cottage cheese and it did not contain $L$. monocytogenes in the present study.

Many outbreaks have been traced to dairy products such as pasteurized milk in Boston, U.S.A., ${ }^{7}$ soft cheese in California, U.S.A. ${ }^{40}$ Therefore contaminated processed milk products as found in the present study pose the greatest threat from $L$. monocytogenes because they are consumed without further treatment.

In conclusion it can be said that those engaged in the food industry should take adequate measures to eliminate the organism during processing, avoid post processing contamination and check sample products for contamination.

\section{Acknowledgement}

The authors acknowledge the financial assistance given by University of Kelaniya and NARESA.

\section{References}

1. Gilbert R.J., Hall S.M. \& Taylor A.G. (1989). Listeriosis update. Public Health Laboratory Service Microbiology Digest 6: 33-38.

2. Gray M.L. \& Killinger A.H. (1966). Listeria monocytogenes and Listeria infections. Bacteriological Reviews 30: 309-382.

3. Shahamat M., Seaman A. \& Woobine M. (1980). In Gould D.W. \& Coory E.L. (Eds) Survival in extremes of environment. Academic Press. London 227237.

4. Buchanan R.L., Stahl H.G. \& Whiting R.C. (1989). Effects and interactions of temperature, $\mathrm{pH}$, atmosphere, sodium chloride and sodium nitrite on the growth of Listeria monocytogenes. Journal of Food Protection 52: 844-851. 
5. Junttila J., Hirn J., Hill \& Nurmi E. (1989). Effect of different levels of nitrite and nitrate on the survival of Listeria monocytogenes during the manufacture of fermented sausage. Journal of Food Protection 52: 158-161.

6. Schwartz B., Ciesielski C.A., Broome C.V., Gaventa S., Brown G.R., Gellin B.G., Hightower A.W., Mascola L. \& the Listeriosis Study Group (1988). Association of sporadic listeriosis with consumption of uncooked hot dogs and undercooked chicken. Lancet ii: 779-782.

7. Fleming D.W., Cochi S.L., Mcdonald K.L., Brondum J., Hages P.S., Plikaytis B.D., Holmes M.B., Audurer A., Broome C.V. \& Reingold A.L. (1985). Pasteurized milk as a vehicle of infection in an outbreak of listeriosis. New England Journal of Medicine 312: 404-407.

8. Ho J.L., Shands K.N., Friendland G., Eckind P. \& Fraser D.W. (1986). An outbreak of type $4 \mathrm{~b}$ Listeria monocytogenes infection involving patients from eight Boston hospitals. Archives of International Medicine 146:520-524.

9. Azadin B.S., Finnerty G.T.R. \& Pearson A.D. (1989). Cheese borne listeria meningitis in immunocompetent patients. Lancet i: 322-323.

10. Gellin B.G. \& Broome C.V. (1989). Listeriosis. Journal of American Medical Association 261: 1313-1320.

11. Lovett J., Francis D.W. \& Hunt J.M. (1987). Listeria monocytogenes in raw milk: detection, incidence and pathogenicity. Journal of Food Protection 50: 188-192.

12. Curtis G.D.W., Mitchel R.G., King A.F. et al. (1989a). A selective differential medium for the isolation of Listeria monocytogenes. Letters in Applied Microbiology 7: 17-21.

13. McLauchlin J. (1987). Listeria monocytogenes: recent advances in the taxonomy and epidemiology of Listeriosis in humans. Journal of Applied Bacteriology 63: 1-11.

14. Rodriguez L.D., Boland J.A.V., Garayzabal Fernandez J.F., Tranchant P.E., Lucia E.G., Ferri E.F.R. \& Fernandez G.S. (1986). Microplate technique to determine haemolytic activity for routine typing of Listeria species. Journal of Clinical Microbiology 24: 99-103.

15. Bailey J.S., Fletcher D.L. \& Cox N.A. (1989). Recovery and serotype distribution of Listeria monocytogenes from broiler chickens in the southeastern United States. Journal of Food Protection 52: 148-150.

16. Skovgaard N. \& Morgen C.A. (1988). Detection of Listeria species in faeces from animals, in feeds, and in raw foods of animal origin. International Journal of Food Microbiology 6: 229-242. 
17. Breer C. (1988). Occurrence of Listeria species in different foods. WHO report of the Working Group on Foodborne listeriosis. Geneva, Switzerland, Feb. 15-19.

18. Genigeorgis C.A., Dutulescu D. \& Garayzabal J.F. (1989). Prevalence of Listeria species in poultry meat at the supermarket and slaughter house level. Journal of Food Protection 52: 618-624.

19. Hudson W.R. \& Mead G.C. (1989). Listeria contamination at a poultry processing plant. Applied Microbiology 9: 211-214.

20. Gilbert R.J., Miller K.L. \& Roberts D. (1989). Listeria monocytogenes and chilled foods. Lancet $\mathbf{i}: 383-384$.

21. Stroupe W.H., Prosser J.T., Tierney J.T., Bryner J.H. \& Dickerson R.W. (1988). Effect of High Temperature Short Time Pasteurization on Listeria monocytogenes. Abstracts of 75th Annual Meeting of the International Association of Milk Food and Environmental Sanitarians, Tampa, Florida.

22. Lovett J., Bradshaw J.G., Francis D.W., Crawford R.G., Donnelly C.W., Murthy G.K. \& Wesley I.V.(1988). Efficacy of High Temperature Short Time Pasteurization for inactivation of Listeria monocytogenes in milk. Abstracts of 75 th Meeting of the International Association of Milk Food and Environmental Sanitarians, Tampa, Florida.

23. Farber J.M., Sanders G.W. \& Malcom S.A. (1988b). The presence of Listeria species in raw milk in Ontario. Canadian Journal of Microbiology 34: 55-100.

24. Kerr K.G., Dealler S.F. \& Lacey R.W. (1988). Materno-fetal listeriosis from cook-chill and refrigerated food. Lancet ii: 1133.

25. Sclech W.F., Lavigne P.M., Bortolussi R.A., Allen A.C., Haldane E.V., Wort A.J., Hightower A.W., Johnson S.E., King S.H., Nicholls E.S. \& Broome C.V. (1983). Epidemic listeriosis evidence for transmission by food. New England Journal of Medicine 308: 203-206.

26. Souef P., Le N. \& Walters B.N.J. (1981). Neonatal listeriosis: a summer outbreak. Medical Journal of Australia 2: 188-191.

27. Heisick J.E., Havrell F.M., Peterson E.H., MaLaughlin S., Wagner D.E., Wesley I.V. \& Bryner J. (1989). Comparison of four procedures to detect Listeria species in foods. Journal of Foad Protection 52: 154-157.

28. Welshimer H.J. (1960). Survival of Listeria monocytogenes in soil. Journal of Bacteriology 80: 316-320. 
29. Picard-Bonnand E., Collin J. \& Carbonnelle B. (1988). Study on the preservation of Listeria monocytogenes in different sorts of soil. Abstracts of the 10th International Symposium on Listeriosis p. 97. The University Medical School P'ecs, Hungary.

30. Sizmur K.I. \& Walker C.W. (1988). Listeria in prepacked salads. Lancet i: 1167.

31. Beckers H.J., Soentero P.S.S. \& Delfgon-van Asch E.H.M. (1989). The occurrence of Listeria monocytogenes in soft cheeses and raw milk and its resistance to heat. International Journal of Food. Microbiology 4: 249-256.

32. Fenlon D.R. \& Wilson J. (1989). The incidence of Listeria monocytogenes in raw milk from farm bulk tanks in North and East Scotland. Journal of Applied Bacteriology 66: 191-196.

33. Rodriguez L.D., Garayzabal J.F.D., Boland J.A.V., Ferri E.R. \& Fernandez G.S. (1985). Abstract. Isolation de micro-organisms du genre Listeria a partir de lait cru destine a la consommation humaine. Canadian Journal of Microbiology 31: 938-941.

34. Bradshaw J.G., Peeler J.T., Corwin J.J., Hunt J.M. \& Twedt R.M. (1987). Thermal resistance of $L$. monocytogenes in dairy products. Journal of Food Protection 50: 543-544.

35. Lovett J., Wesley I.V., Vandermaaten M.J., Bradshaw J.G., Francis D.W., Crawford R.G., Donnelly C.W. \& Masser J.W. (1990). High Temperature Short Time Pasteurization inactivates Listeria monocytogenes. Journal of Food Protection 53: 734-738.

36. Mackey B.M. \& Bratchell N. (1988). The heat resistance of Listeria monocytogenes. Letters in Applied Microbiology 9: 89-94.

37. Greenwood M.H., Roberts D. \& Burden P. (1991). The occurrence of Listeria species in milk and dairy products: a national survey in England and Wales. International Journal of Food Microbiology 12: 197-206.

38. Harvey J. \& Gilmour A. (1992). Occurrence of Listeria species in raw milk and dairy products produced in Northern Ireland. Journal of Applied Bacteriology 72: 119-125.

39. Pini P.N. \& Gilbert R.J. (1988). The occurrence in the U.K. of Listeria species in raw chickens and soft cheeses. International Journal of Food Microbiology 6: $317-326$.

40. Linnan M.J., Mascolla L., Lou X.D., Goulet V., May S., Salminen C., Hird D.W., Hayes P., Weaver R., Audurier A., Plikaytis B.D., Fannin S.L., Kleks A. \& Broome C.V. (1988). Epidemic listeriosis associated with Mexican-style cheese. New England Journal of Medicine 319: 823-828. 